\title{
Temperature and Time Dependent Analysis of Tungsten Inert Gas Welding of Low Carbon Steel Plate using Goldak Model Heat Source
}

\author{
${ }^{1}$ OWUNNA, I; ${ }^{1 * I K P E, ~ A E ; ~}{ }^{2}$ ACHEBO, JI \\ ${ }^{1}$ Department of Mechanical Engineering, ${ }^{2}$ Department of Production Engineering University of Benin, P.M.B. 1154, Nigeria \\ *Corresponding Author Email: ikpeaniekan@gmail.com; josephachebo@yahoo.co.uk; Ikechukwu.owunna@uniben.edu
}

\begin{abstract}
In this study, temperature and time dependence analysis was carried out on Tungsten Inert Gas (TIG) Welding of AISI 1020 Low Carbon Steel Plate of $10 \mathrm{~mm}$ thickness. The TIG welding parameters deduced from design of experiment for current ranging from 96-213 A, voltage ranging from 16-25 V and gas flow rate ranging from 11-19 L/min was used as input variables for the welding experimentation and simulation using Finite Element Method (FEM) based on Goldak model heat source. There was proximity in the regression plot of temperature outputs for both the experimental and FEM predicted values. The temperature and time dependence transient thermal analysis was simulated for 20 seconds at welding speed of $1.5 \mathrm{~mm} / \mathrm{s}$ in steps of 2.5 seconds for each heat source and the result revealed that at each increasing step, the heat distribution characterized by intense heat, phase transformation and alteration in mechanical properties gradually formed a spiral transient patterns from the weldment known as Heat Affected Zone (HAZ). Hence the longer the arc heat at a given weldment the wider the HAZ which result in high residual stress build-ups, undercut and other welding defects that hampers the welded component in service condition.
\end{abstract}

\section{DOI: https://dx.doi.org/10.4314/jasem.v22i11.2}

Copyright: Copyright (C) 2018 Owunna et al. This is an open access article distributed under the Creative Commons Attribution License (CCL), which permits unrestricted use, distribution, and reproduction in any medium, provided the original work is properly cited.

Dates: Received: 02 October 2018; Revised: 26 October 2018; Accepted 09 November, 2018

Keywords: Welding, Temperature, Time, Welding current, Heat distribution, Flat plate

Arc welding process such as Tungsten Inert Gas (TIG) is a process that involves the fusion of two or more materials together through localised application of heat and its dissipation through conduction into the parent metal (Parmar, 1999). The area surrounding the fusion line is known as Heat Affected Zone (HAZ), an area that is not completely heated to cause melting but not withstanding has been affected by the welding thermal cycle. According to Kamble and Rao (2013), heat distribution around the weldment usually alters the chemical and mechanical properties which depends upon the chemical composition of the bead and its geometry. Depending on the peak welding temperature attained by the arc welding process, HAZ in steels can be sub-divided into the following zones namely; Under Bead Zone i.e., that part of HAZ which is heated to beyond the critical temperature of grain growth and extend up to the fusion boundary zone, Grain Growth Zone, beyond $1150^{\circ} \mathrm{C}$ to peritectic temperature, Grain Refined Zone, 950 to $1150^{\circ} \mathrm{C}$, i.e., beyond A3 up to grain refined temperature range, Partially Transformed Zone, 750 to $950^{\circ} \mathrm{C}$, i.e., between A1 and A3 temperature, Zone of Spherodized Carbides, 550 to $750^{\circ} \mathrm{C}$, i.e., below $\mathrm{A} 1$, Zone of Unchanged Base Material, up to $550^{\circ} \mathrm{C}$ (Sura and Mittal, 2015). During the welding process of steel structures, a localized fusion is formed on the welded joint due to heat input from the welding arc which consequently produce a non-uniform temperature distribution across the welded joint as a result of heat conduction during the thermal cycle. Depending on the test method adopted, high financial investment may be required to procure the equipment to subject the specimen to standardized experimentation for proper understanding of the transient temperature field during welding operation. However, there are many numerical techniques such as Finite Element Method (FEM), boundary element and volume method, finite strip and volume method and Boundary integral methods that can be adopted for estimating the approximate solutions of acceptable tolerance (Fallah et al., 2000). Considering the computation time, problems of inaccuracy and irregular patterns in the HAZ encountered in the past, FEM has been investigated in recent times and considered as a potential tool that can provide ideal solutions for unravelling the various defects bedevilling welding processes. To understand the heat flux mechanism and heat source used for Tungsten Inert Gas (TIG) welding process, Vemanaboina et al. (2014) used the finite element transient thermal approach to analyse the base metal condition, temperature fields at various points within the weld pool and around the pool region (ie. HAZ). A 3D finite element transient model was developed by Vishnu et al. (2014) to predict the trend of temperature distribution during TIG double side arc

*Corresponding Author Email: ikpeaniekan@gmail.com; josephachebo@yahoo.co.uk;

Ikechukwu.owunna@uniben.edu 
welding process on low carbon steel plate. Vijay et al. (2016) carried out Finite element thermal analysis on butt joint of SS340 stainless steel plate using TIG welding process, and the temperature obtained in the simulation correlated with the experimental temperature measured with thermocouple. Olabamiji and Adedayo (2016) carried out ne-dimensional finite element (FE) modelling of the temperature profile in axi-symmetric flash butt welded steel rods by examining the welding conditions such as the effect of pre-heat temperature, flash temperature, flash duration, and material geometries on temperature profile at various points along the rod and the results compared with experimental result showed proximity. In this study, temperature and time dependence analysis of tungsten inert gas welding of mild steel Plate was conducted using Goldak Model heat source.

\section{MATERIALS AND METHOD}

Equipment used include: (i) Power saving machine for cutting the materials, (ii) Vertical milling machine for milling the angles, (iii) G-clamp for clamping the work pieces, (iv) Welding machine, (v) Welding electrode, (vi) K-type Thermocouple, (vii) $10 \mathrm{~mm}$ flat plate, (viii) Solid Works Software, (ix) Sand paper and Acetone

Method: $10 \mathrm{~mm}$ thickness of AIS1 1020 low carbon steel was sourced locally and was cut to a dimension of $60 \times 30 \mathrm{~mm}$ (length $\mathrm{x}$ width) each. Sand paper was used to smoothen each of the two specimen to eliminate all possible coatings, corrosion or rust that may have accumulated on the material. The two steel plates where chamfered at 30 degrees, after which, fusion welding was used to join the two plates together to form an angle of 60 degree with $2 \mathrm{~mm}$ depth. The milling of the angle was done using a vertical milling machine. The welding was carried out with the plates properly clamped to avoid misalignment during welding process. Prior to welding, surface of the samples to be welded were chemically cleaned using acetone to eliminate surface contamination and welding was applied on the flat plates. The welding parameters were deduced from design of experiment (DOF), and were used in carrying out the welding process for 20 runs with variable voltages ranging from $16-25 \mathrm{~V}$, variable currents ranging from 96-213A and variable gas flow rates ranging from 11-19 L/min respectively. K-type thermocouples were attached to the surface of the workpiece and the temperature was recorded at 20 points as the arc passed along the workpiece. Also, the welding torch passed over the plate at a height of $2.5 \mathrm{~mm}$ from the workpiece at constant velocity of $1.72 \mathrm{~mm} / \mathrm{s}^{-1}$. For the FEM, the standard AISI 1020 was used for the modelling the low carbon steel plate considering the temperature dependent properties of the specimen. However, mesh control was applied to the heat source, while curvature based mesh was used due to the ellipsoidal shape of the heat source. The model information is presented in Table 1. The simulation was run for 20 runs designed by using the design of experiment (Centre Composite Design Method).

Table 1. Model Information for $10 \mathrm{~mm}$ AISI 1020 Flat Plate

\begin{tabular}{ll}
\hline Study name: TIG WELDING & Mesher Used: Curvature based mesh \\
\hline Analysis type: Thermal (Transient) & Jacobian points: 4 Points \\
Mesh type: Solid Mesh & Maximum element size: $3.4556 \mathrm{~mm}$ \\
Solver type: FFEPlus & Minimum element size: $0.69112 \mathrm{~mm}$ \\
Solution type: Transient & Total Nodes: 218728 \\
Total time: 20 Seconds & Total Elements: 154350 \\
\hline
\end{tabular}

Heat Source Analysis: For welding processes in which the momentum transfer effect of the arc on the weld pool is large, Goldak et al. (1984) derived a model to describe the volumetric heat flux acting on a plate due to applied welding arc heat. For arc welds, accurate results are obtained with a power density distribution in which surfaces of constant power density are ellipsoids and on radial lines the power density obeys Gaussian distribution. In order to overcome the discrepancy between the experimentally measured and predicted temperature gradients in front and behind the arc, two ellipsoidal heat sources were combined as shown in Fig 1, the front half of the source is the quadrant of one ellipsoidal source and the rear half of the heat source is the quadrant of another ellipsoidal heat source.

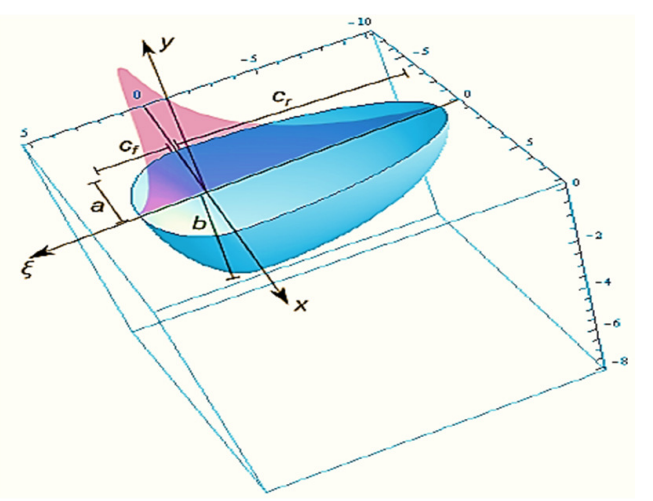

Fig. 1. Double ellipsoidal volumetric heat source

The moving heat source was modeled according to Goldak model. From the Goldak heat source model, 
the volumetric heat flux for a point in the domain $\Omega$ is given by equation 1 ;

$q_{G}(x, y, \xi)=$
$\left\{\begin{array}{l}\frac{6 \sqrt{3 Q r_{f}}}{a b c_{f} \pi \sqrt{\pi}} \exp \left[-3\left(\frac{x^{2}}{a^{2}}+\frac{y^{2}}{b^{2}}+\frac{\xi^{2}}{c_{f}^{2}}\right)\right] \forall(x, y, \xi \geq 0) \in \Omega \\ \frac{6 \sqrt{3 Q r_{r}}}{a b c_{r} \pi \sqrt{\pi}} \exp \left[-3\left(\frac{x^{2}}{a^{2}}+\frac{y^{2}}{b^{2}}+\frac{\xi^{2}}{c_{f}^{2}}\right)\right] \forall(x, y, \xi<0) \in \Omega\end{array}\right\}$

Where, $r_{f}$ and $r_{r}$ are the heat input proportions in the front and rear ellipsoid quadrants, $Q$ is the energy input rate from the arc given by equation $2, a b c_{r}$ and $c_{r}$ represent the radii of the flux distribution.

$\mathrm{Q}=\eta V I$

Where, $\eta \mathrm{V}$ and I represent the efficiency, arc voltage and arc current.

Transient heat conduction by the flat plate during welding sequence is expressed by the linear partial differential equation given by equation 3 ; $\rho c \frac{\partial T}{\partial t}-k \nabla^{2} T=q$

Where, $\rho, \mathrm{k}$ and $c$ denotes the mass density, thermal conductivity, specific heat capacity and $q$ is the rate of internal heat generation which is considered as applied heat source. However, the natural boundary condition for conduction and radiation heat taking place in the welded material during welding cycle is by equation 4

$k \frac{\partial T}{\partial_{n}}-q+h\left(T-T_{o}\right)+\sigma \varepsilon\left(T^{4}-T_{o}^{4}\right)=0$

Where, $\mathrm{T}$ denotes the temperature variable, $\mathrm{q}$ is the heat flux, $\mathrm{h}$ is the coefficient of heat conduction, $\sigma$ is the melt pool emissivity, $\varepsilon$ is Stephan-Boltzmann constant. The basic solution of the heat equation in one dimension is given by Green's function in equation 5;

$K\left(x-x^{\prime}, t-t^{\prime}\right)=\frac{1}{\sqrt{4 \pi \alpha\left(t-t^{\prime}\right)}} \exp \left[-\frac{\left(x-x^{\prime}\right)^{2}}{4 \alpha\left(t-t^{\prime}\right)}\right] \forall\left(x-x^{\prime}, t-t^{\prime} \geq 0\right) \in \Omega$

Where $\alpha$ is the thermal diffusivity given by equation 6 ;

$$
\frac{k}{\rho c_{p}}
$$

However, two and three dimensional Green's functions are obtained by multiplying onedimensional Green's functions by the Cartesian coordinates, of which the three dimensional basic solution $K\left(x-x^{\prime}, y-y^{\prime}, z-z^{\prime}, t-t^{\prime}\right)$ for the heat equation is given by Green's function in equation 7;

$K=\frac{1}{\left(4 \pi \alpha\left(t-t^{\prime}\right)\right)^{3 / 2}} \exp \left[-\frac{\left(x-x^{\prime}\right)^{2}+\left(y-y^{\prime}\right)^{2}+\left(z-z^{\prime}\right)^{2}}{4 \alpha\left(t-t^{\prime}\right)}\right] \forall\left(x-x^{\prime}, y-y^{\prime}, z-z^{\prime}, t-t^{\prime} \geq 0 \in \Omega\right)$

If only conduction is being considered the weldment can be modelled by considering insulating boundary

shown, via the Laplace transform method, that the Green's function that describes this, $G\left(x-x^{\prime}, y-y^{\prime}, z-z^{\prime}, t\right.$ conditions at every face. In three dimensions it can be

$\left.t^{\prime}\right)$, is given by equation 8 ;

$$
G=\frac{1}{\left(4 \pi \alpha\left(t-t^{\prime}\right)\right)^{3 / 2}}\left\{\begin{array}{c}
\sum_{n_{1}=-\infty}^{n_{1}=\infty}\left[\exp \left[-\frac{\left(2 n_{1} B+x-x^{\prime}\right)^{2}}{4 \alpha\left(t-t^{\prime}\right)}\right]+\exp \left[-\frac{\left(2 n_{1} B+x+x^{\prime}\right)^{2}}{4 \alpha\left(t-t^{\prime}\right)}\right]\right] \\
\mathrm{x} \sum_{n_{2}=-\infty}^{n_{2}=\infty}\left[\exp \left[-\frac{\left(2 n_{2} D+y-y^{\prime}\right)^{2}}{4 \alpha\left(t-t^{\prime}\right)}\right]+\exp \left[-\frac{\left(2 n_{2} D+y+y^{\prime}\right)^{2}}{4 \alpha\left(t-t^{\prime}\right)}\right]\right] \\
\mathrm{x} \sum_{n_{3}=-\infty}^{n_{3}=\infty}\left[\exp \left[-\frac{\left(2 n_{3} L+z-z^{\prime}\right)^{2}}{4 \alpha\left(t-t^{\prime}\right)}\right]+\exp \left[-\frac{\left(2 n_{3} L+z+z^{\prime}\right)^{2}}{4 \alpha\left(t-t^{\prime}\right)}\right]\right]
\end{array}\right\}
$$

During welding operation, temperature variation across the workpiece may result in expansion or retraction. $B, D$ and $L$ are the spatial extent of the plate in the $x, y$ and $z$ directions respectively. The thermal effects as proposed by hooks law is given by the relationship in equation 9

$$
\left[\begin{array}{c}
\varepsilon_{x x} \\
\varepsilon_{y y} \\
\varepsilon_{z z} \\
\Upsilon_{x y} \\
\Upsilon_{x z} \\
\Upsilon_{y z}
\end{array}\right]=\frac{1}{E}\left[\begin{array}{cccccc}
1 & -v & -v & 0 & 0 & 0 \\
-v & 1 & -v & 0 & 0 & 0 \\
-v & -v & 1 & 0 & 0 & 0 \\
0 & 0 & 0 & (1+v) & 0 & 0 \\
0 & 0 & 0 & 0 & (1+v) & 0 \\
0 & 0 & 0 & 0 & 0 & (1+v)
\end{array}\right]\left[\begin{array}{c}
\sigma_{x x} \\
\sigma_{y y} \\
\sigma_{z z} \\
\sigma_{x y} \\
\sigma_{x z} \\
\sigma_{y z}
\end{array}\right]+\alpha \Delta T\left[\begin{array}{l}
1 \\
1 \\
1 \\
0 \\
0 \\
0
\end{array}\right]
$$




\section{RESULT AND DISCUSSION}

The welding input parameters included current, voltage and gas flowrate which were deduced from design of experiment (DOF) for 20 runs, in order to obtain the output variables (Experimental Temperature and FEM Predicted Temperature) presented in Table 2. Regression plot for the Temperature outputs is shown in Fig 2.

Table 2. Experimental and FEM Predicted Temperature Results

\begin{tabular}{lllllc}
\hline $\begin{array}{l}\text { Weld } \\
\text { Runs }\end{array}$ & $\begin{array}{l}\text { Current } \\
(\mathbf{A})\end{array}$ & $\begin{array}{l}\text { Voltage } \\
(\mathbf{V})\end{array}$ & $\begin{array}{l}\text { Gas Flow } \\
\text { Rate }(\mathbf{L} / \mathbf{m i n})\end{array}$ & $\begin{array}{l}\text { Experimental } \\
\text { Temperature }\left({ }^{\mathbf{}} \mathbf{C}\right)\end{array}$ & $\begin{array}{l}\text { FEM Predicted } \\
\text { Temperature }\left({ }^{\mathbf{C}} \mathbf{C}\right)\end{array}$ \\
\hline 1 & 155.00 & 22.00 & 15.50 & 298 & 282.32 \\
2 & 155.00 & 22.00 & 15.50 & 287 & 282.32 \\
3 & 155.00 & 22.00 & 15.50 & 265 & 282.32 \\
4 & 155.00 & 22.00 & 15.50 & 264 & 282.32 \\
5 & 155.00 & 22.00 & 15.50 & 265 & 282.32 \\
6 & 155.00 & 22.00 & 15.50 & 265 & 282.32 \\
7 & 155.00 & 27.05 & 15.50 & 319 & 325.13 \\
8 & 96.14 & 22.00 & 15.50 & 393 & 396.35 \\
9 & 155.00 & 22.00 & 11.30 & 300 & 308.74 \\
10 & 155.00 & 16.95 & 15.50 & 308 & 305.11 \\
11 & 213.86 & 22.00 & 15.50 & 423 & 412.61 \\
12 & 155.00 & 22.00 & 19.70 & 253 & 243.28 \\
13 & 120.00 & 19.00 & 18.00 & 251 & 246.28 \\
14 & 190.00 & 19.00 & 13.00 & 365 & 360.21 \\
15 & 190.00 & 25.00 & 13.00 & 354 & 349.24 \\
16 & 120.00 & 25.00 & 18.00 & 308 & 302.24 \\
17 & 190.00 & 25.00 & 18.00 & 323 & 315.77 \\
18 & 120.00 & 19.00 & 13.00 & 325 & 319.72 \\
19 & 120.00 & 25.00 & 13.00 & 375 & 375.81 \\
20 & 190.00 & 19.00 & 18.00 & 380 & 381.53 \\
\hline
\end{tabular}

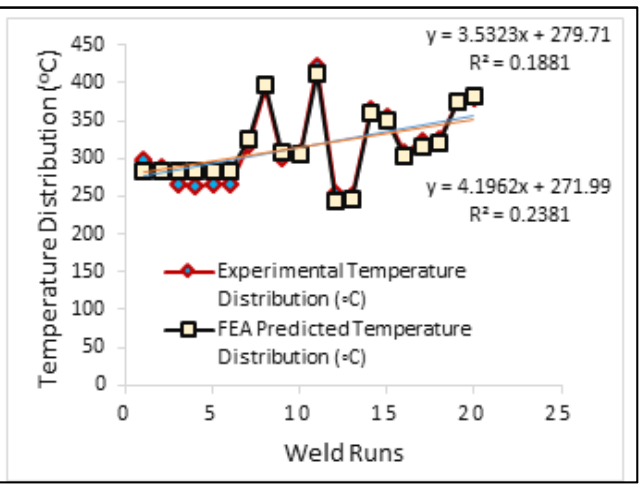

Fig. 2. Regression plot of Temperature outputs

A transient thermal analysis was used to simulate the weld for 20 seconds at a welding speed of $1.5 \mathrm{~mm} / \mathrm{s}$ with a steps of 2.5 seconds for each heat source. As shown in Fig 3-10, the temperature was distributed as the heat source varied across the welded metal at different time intervals. The momentum heat transfer effect of the arc on the weld pool is based on the model proposed by Goldak et al. (1984) which describes the volumetric heat flux acting on the AISI 1020 low carbon steel plate due to the arc heating effect. Figure 3-10 represents the temperature distribution across a $10 \mathrm{~mm}$ AISI 1020 low carbon steel plate with TIG welding time dependence. From the colour chart in these Figures (3-10), red colour indicates the highest temperature distribution on the welded metal, royal blue indicates the minimum temperature on the welded metal, sky blue indicates the temperature at which the welded metal begins to respond to the arc heating, aqua $(\mathrm{SVG})$ blue indicates further responses of the welded metal from the temperature signified by the sky blue colour etc.

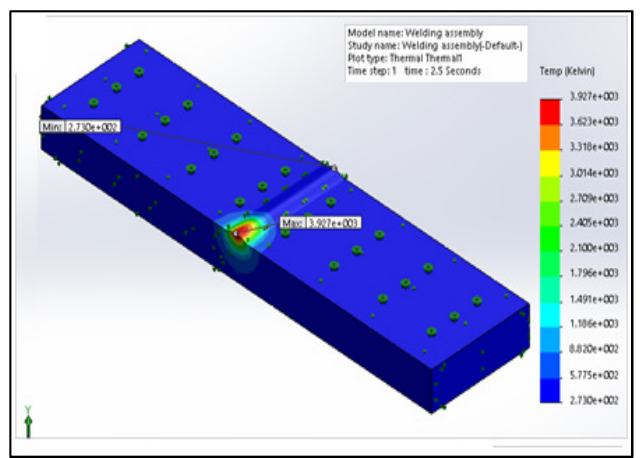

Fig. 3. Temperature Distribution at 2.5 Seconds

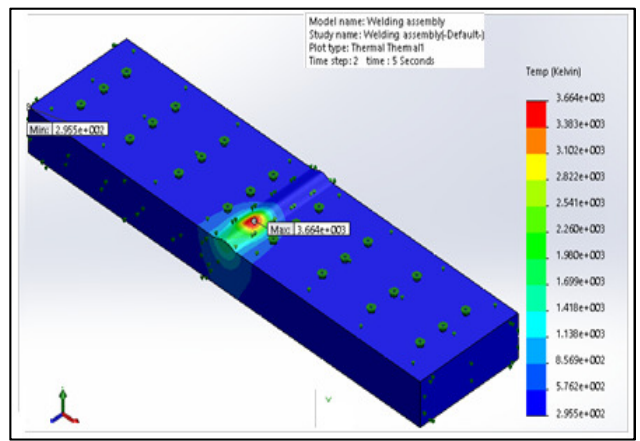

Fig. 4. Temperature Distribution at 5 Seconds 


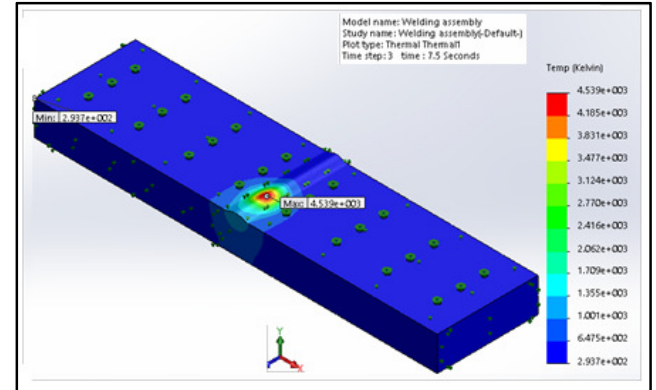

Fig. 5. Temperature Distribution at 7.5 Seconds

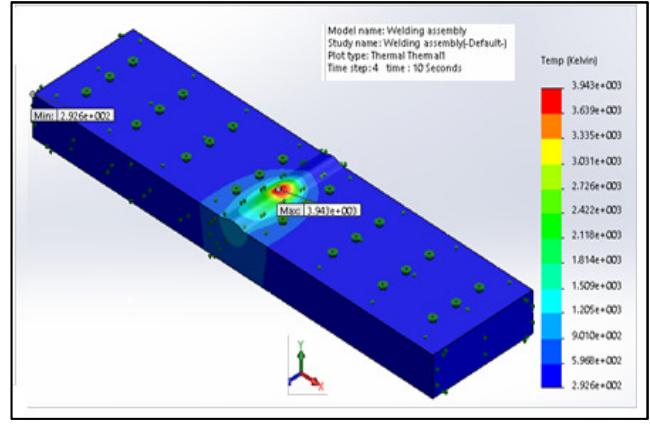

Fig. 6. Temperature Distribution at 10 Seconds

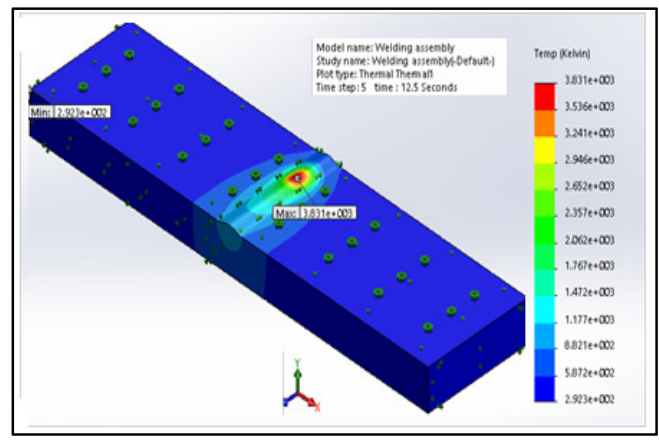

Fig. 7. Temperature Distribution at 12.5 Seconds

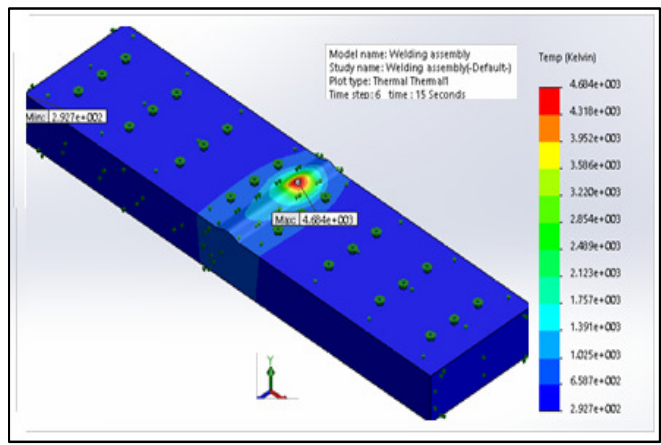

Fig. 8. Temperature Distribution at 15 Seconds

Apart from the red and royal blue colour, every other colours shown on the chart represent the Heat Affected Zones (HAZ) as cited in the introductory section of this study. It can be observed that at $2.5 \mathrm{sec}$, the HAZ is minimal, but the HAZ increased subsequently with the welding time, indicating that the amount of time which the arc electrode is applied on the welded metal plays a significant role in the trend of welding defects evolving on the fusion zone. During welding the welding process carried out in this study, it was observed that higher arc length which is a function of continuous increase of the welding current (amperage) produced more heat than required for the metal fusion process and this to some extent can influenced the geometry of the heat affected zone. This can be justified by referring to Fig 11, where the geometry of the HAZ tends to widen as the welding amperage increases.

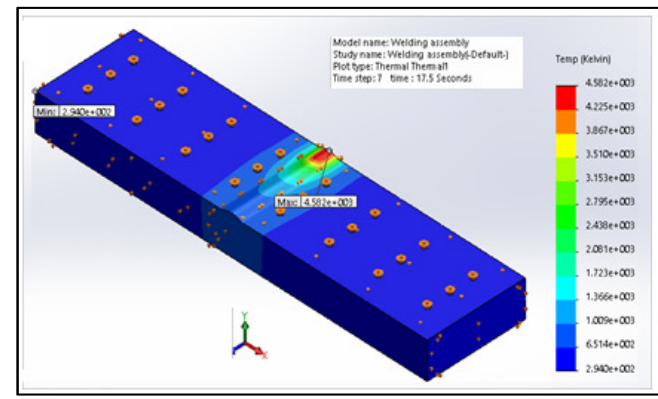

Fig. 9. Temperature distribution at 17.5 seconds

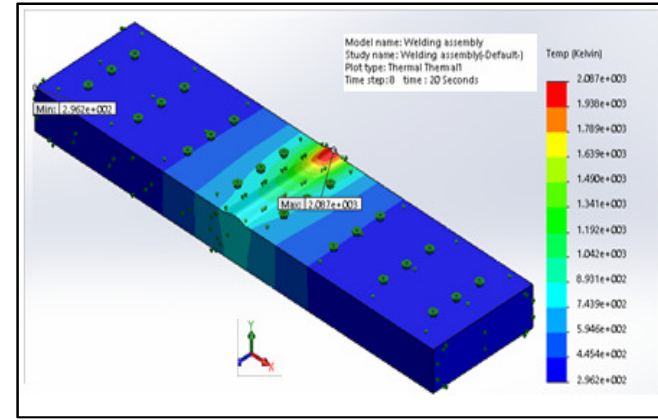

Fig. 10. Temperature distribution at 20 seconds
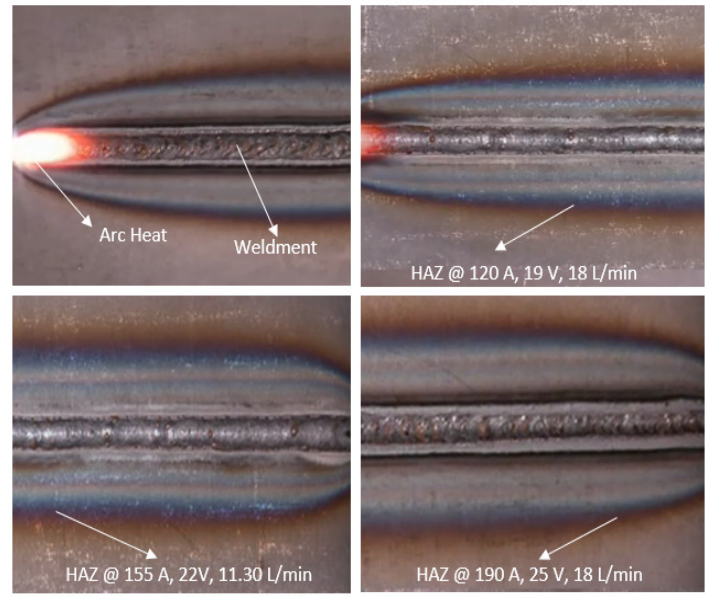

Fig. 11. Trend of Heat Affected Zones with Corresponding Amperages 
Hence, it is important to adequately regulate the current as well as other welding parameters such as gas flow rate and voltage for optimum welding outcome. In this case, water-cooled GTAW touch was used for welding amperage above $150 \mathrm{amps}$, and that helped control the heat that built up around the weldment. Generally, excessive heat build-up around the weldment and base metal can result in the formation of brittle intermetallic phases, formation of coarse columnar grains, burnout or excessive melt-through during the welding process and this phenomenon signifies a bad weld that may be susceptible to adverse corrosion effect and premature failure of the welded material (Wei et al., 2015; Arivarasu et al., 2014).

The higher welding amperage in effect can result in undercut due to welding operations conducted with relatively high amperage or relatively long arc length which would leave a groove in the base metal along either sides of the bead, thereby, causing residual stress build-up and reduction in the strength of the weldment. In other words, welding operation with too high an amperage will produce a wide flat bead with no defined pattern and characterized by overheating that can cause brittleness of the welded metal which is a sign of weld failure (Ikpe et al., 2017). Melting which is a function of the intensity of heat input is an essential requirement in any welding operation, as the arc heat causes initial melting of the welded metal at the fusion zone and continuous melting which is allowed to solidify in time thereby, forming one whole piece. The melting range condition which is also known as the "the plastic range" or "mushy state" is a useful gauge that determines how quickly a phase transformation (in terms of melting) takes place on the application of arc welding heat. Depending on the degree of response to applied heat, the atoms and electrons within the microstructure of the material continues to absorb heat until a point is reached where thermal equilibrium or saturation is attained and the material begins to melt. At thermal equilibrium, the atoms and electrons begin to melt along its lattice until the material liquefies completely at critical temperatures. This thermal distribution is primarily a function of the material response to welding temperature and heat transfer in the material. However, melting rate and heat transfer in the material during the welding process is a function of the melting profile of the material, thickness, and surface area of the material.

For the AISI 1020 low carbon steel plate heat transfer during the welding process occurs through conduction and radiation. Conduction is the transfer of heat from one part of the same body or from one body to the other in physical contact with it, without significant displacement of atoms constituting such bodies. In principle, all bodies will continue to emit electromagnetic radiation except their temperature is absolute zero, and the higher the amount of temperature, the higher the temperature gradient, the greater the rate at which energy is radiated (Eastop and McConkey, 2004). In arc welding applications such as TIG where two or more metals are joined together through localized application of heat, there is a net transfer of energy between the welded materials, and this form of energy tranfer satisfies the expression given by equation 3 and 4 . Heat transfer in a given welded material also relate to Fourier's law of conduction which states that the rate of heat transfer through a single homogeneous body is directly proportional to the area of the section at right angles to the direction of heat flow, and to the change of temperature with respect to the length of the path of the heat flow. The relationship between the material response to heat input cannot be fully unravel without considering the solidus and liquidus temperature of the material which for the AISI low carbon steel plate used in this study is shown in Fig 12;

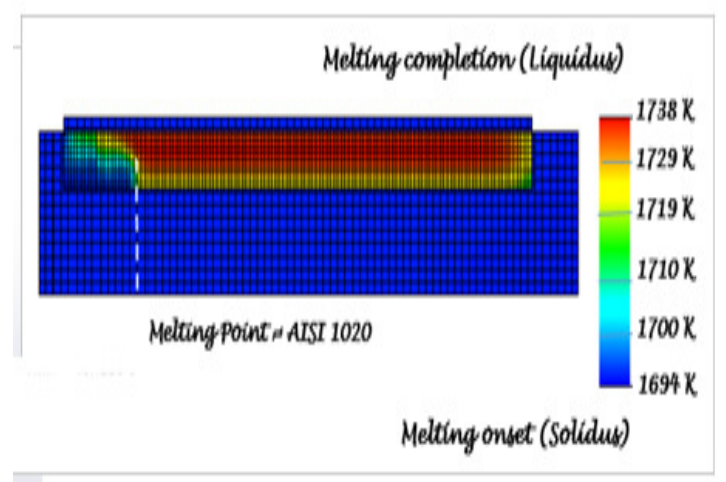

Fig. 12. Melting Profile for AISI 1020 Low Carbon Steel

The temperature at which solid metals begin to melt, but not completely melted is known as the solidus temperature while liquidus temperature quantifies the temperature at which a metal is completely melted. Moreover, the metal is partly solid and partly liquid at temperatures between the solidus phase and liquidus phase whereas, the span of temperature from the point at which the metal begins to liquefy to the point at which the entire welding zone becomes molten liquid is known as melting range which for the AISI 1020 low carbon steel plate used in this study can be determined from Fig 12. However, below the solidus temperature phase, there was no phase transformation as the welded metal was continuously absorbing the heat applied from the welding but phase transformation occurred at the solidus temperature phase where the welded metal began to melt as a result of the welding heat. This can be observed in Fig 12, where the solidus temperature phase $(1694 \mathrm{k})$ is identified as melting onset. Subsequent increase in 
temperature led to further transformation in the melting phase of the metal. This can be observed in the colour chart in Fig 12, where the melting rate after solidus temperature was designated as light blue colour at a temperature of $1700 \mathrm{k}$, lemon colour at a temperature of 1710, yellow colour at a temperature of $1719 \mathrm{k}$, orange colour at a temperature of $1729 \mathrm{k}$ and red colour at a melting temperature of $1738 \mathrm{k}$ respectively.

Conclusion: Temperature values generated from FEM and experimental methods graphically maintained the same pattern and trend. This implies that FEM can be employed to emulate welding routes before practical applications. It has been established in this study that weld bead penetration is highly dependent on welding temperature and time. It has also been shown that, higher welding temperature input and shorter welding time can result in shallow bead penetration while higher welding temperature and longer welding time can accelerate the rate of heat transfer and bead penetration through the parent metal. Since the strength and quality of a good weld is characterized by deeper bead penetration depth, this study serves as a basis for improving the quality and longevity of welded joint in engineering applications.

\section{REFERENCES}

Arivarasu, M; Devendranath, KR; Arivazhagan, N (2014) Comprehensive Studies of High and Low Frequency Pulsing on the Aspect Ratio of Weld Bead in Gas Tungsten Arc Welded AISI 304L Plates, Procedia Eng 97: 871-880.

Eastop, TD; McConkey, A (2004) Applied Thermodynamics for Engineering Technologist, Fourth Edition, Pearson Education Ltd, ISBN:8178085577.

Fallah, NA; Bailey, C; Cross, M; Taylor, GA (2000) Comparison of Finite Element and Finite Volume Methods Application in Geometrically Nonlinear Stress Analysis, Appl Mathematical Modelling, 24(7): 439-455.

Goldak, J; Chakravarti, A; Bibby, M (1984) A new finite element model for welding heat source,
International Journal Metallurgical and Materials Transactions B 15(2): 299-305.

Ikpe, AE; Owunna, I; Ikpe, E (2017) Effects of Arc Voltage and Welding Current on the Arc Length of Tungsten Inert Gas Welding (TIG), Int J of Eng Tech 3(4): 213-221.

Kamble, AG; Rao, RV (2013). Experimental Investigation on the Effects of Process Parameters of GMAW and Transient Thermal Analysis of AlS1 321 Steel. Advances in Manufacturing 1(4): 362-377.

Parmar, RS (1999). Welding Engineering and Technology, First Edition. Khanna Publishers, Delhi, ISBN: 8174090282, 1999.

Sura, N; Mittal, V (2015) Experimental Study on Effects of Process Parameters on HAZ of Plain Carbon Steel Using GMAW, Int $J$ of Latest Research in Sci and Tech 4(2): 167-170.

Vemanaboina, H; Akella, S; Buddu, RK. (2014) Welding Process Simulation Model for Temperature and Residual Stress Analysis, Precedia Material Sci 6: 1539-1546.

Vijay, G; Makwana, J; Ranjan, R (2016) Theremomechanical Analysis in TIG Welding of S.S 304. Int J of Eng Dev and Research 4(2): 1704-1710.

Vishnu, VS; Nadeera, M; Varghese, VM (2014) Numerical Analysis of Effect of Process Parameters on Residual Stress in a Double side TIG Welded Low Carbon Steel Plate, IOSR J of Mech and Civil Eng 2320-334X: 65-68.

Olabamiji, TS; Adedayo, SM (2016) Finite Element Modelling of Temperature Cycles in AxiSymmetric Flash Butt Welded Thin Steel Rods and Experimental Validation. J of Eng Res 21(1): 31-40.

Wei, L; Junjie, M; Fanrong, K; Shuang, L; Kovacevic, R (2015) Numerical Modelling and Experimental Verification of Residual Stress in Autogenous Laser Welding of High Strength Steel, Lasers in Mfg and Materials Processing 2(1): 24-42. 